\title{
COVID-19 and Neonatal Resuscitation
}

In this issue of Neonatology, we publish two papers with suggestions for neonatal resuscitation when the mother is suspected of having COVID-19 infection [1,2]. These papers come from Italy [1] where the COVID-19 pandemic has resulted in many thousands of deaths and from Hong Kong [2] where, in contrast, only 4 lives to date have been lost to the infection. These differences in outcomes between Europe and Asia will need to be explored in future research studies taking into account demographic factors [3] as well as government and medical responses. There is uncertainty about whether the COVID-19 virus can be transmitted vertically from mother to newborn infant either in utero or at birth. Although vertical transmission seems unlikely, there have been reports of early neonatal infection $[4,5]$. Zhu et al. [4] reported some adverse outcomes in 10 babies born to mothers with COVID-19 infection. These adverse outcomes included fetal distress, premature labor, respiratory distress, thrombocytopenia and abnormal liver function, but the neonates themselves tested negative for the virus. It is likely that vertical transmission of the virus did not occur, and the neonatal complications were related to preterm delivery [4]. Zhang et al. [5] in a very recent report could only find 4 infected newborns in China and they presented aged between $30 \mathrm{~h}$ and 17 days after birth suggesting nosocomial infection. These babies had mild or no illness, none needed intensive care, and all seemed to have recovered. Three of the infants had been separated from their mother right after birth and were not breastfed [5].
We hope that you find the recommendations contained in these thoughtful reports from Italy [1] and Hong Kong [2] useful and helpful in planning perinatal care for infants at risk of developing COVID-19 infection. We wish all our readers well in their efforts to combat the effects of this terrible pandemic and salute all those healthcare workers in their dedication to the task. We are convinced that solutions will be found to overcome this deadly virus.

\section{Henry L. Halliday, Editor-in-Chief Christian P. Speer, Editor-in-Chief}

\section{References}

1 Trevisanuto D, Moschino L, Doglioni N, Roehr CC, Gervasi MT, Baraldi E. Neonatal resuscitation where the mother has a suspected or confirmed novel coronavirus (SARS-CoV-2) infection: suggestion for a pragmatic action plan. Neonatology. 2020. DOI: 10.1159/000507935.

$2 \mathrm{Ng}$ PC. Infection control measures for COVID-19 in labour suite and neonatal unit - A commentary. Neonatology. 2020. DOI: $10.1159 / 000508002$.

3 Dowd JB, Andriano L, Brazel DM, Rotondi V, Block P, Ding X, et al. Demographic science aids in understanding the spread and fatality rates of COVID-19 [Online ahead of print]. Proc Natl Acad Sci USA. 2020 Apr; 202004911.

4 Zhu H, Wang L, Fang C, Peng S, Zhang L, Chang G, et al. Clinical analysis of 10 neonates born to mothers with $2019-\mathrm{nCoV}$ pneumonia. Transl Pediatr. 2020 Feb;9(1):51-60.

5 Zhang ZJ, Yu XJ, Fu T, Liu Y, Jiang Y, Yang BX, et al. Novel coronavirus infection in newborn babies under 28 days in China. Eur Respir J. 2020 Apr;2000697. 